\title{
Increased immunoglobulin production in silver catfish (Rhamdia quelen) exposed to agrichemicals
}

\author{
L.C. Kreutz, T.R. Pavan, A.G. Alves, A.G. Correia, B. Barriquel, \\ E.D. dos Santos and L.J.G. Barcellos \\ Laboratório de Virologia e Imunologia, Programa de Pós-Graduação em Bioexperimentação, \\ Universidade de Passo Fundo, Passo Fundo, RS, Brasil
}

\begin{abstract}
Fish vaccination has been increasingly exploited as a tool to control pathogen infection. The production of immunoglobulin following vaccination might be affected by several factors such as management procedures, water temperature, and the presence of xenobiotics. In the present study, we aimed to investigate the kinetics of immunoglobulin production in silver catfish (Rhamdia quelen) inoculated with inactivated Aeromonas hydrophila and kept at two different water temperatures $\left(17.4 \pm 0.4^{\circ}\right.$ or $\left.21.3 \pm 0.3^{\circ} \mathrm{C}\right)$. The effect of a second antigen inoculation and exposure of fish to sublethal concentrations of the herbicides atrazine and glyphosate at $10 \%$ of the lethal concentration ( LC $_{50-96 h}$ ) on specific serum antibodies were also investigated. Antibodies to $A$. hydrophila were detected as early as 7 days post-inoculation and increased steadily up to 35 days. The kinetics of antibody production were similar in fish kept at $17.4 \pm 0.4^{\circ}$ and $21.3 \pm 0.3^{\circ} \mathrm{C}$, and reinoculation of antigen at 21 days after priming failed to increase specific antibody levels. Intriguingly, we found that, in fish exposed to atrazine and glyphosate, the secretion of specific antibodies was higher than in non-exposed inoculated fish. These findings are important for the design of vaccines and vaccination strategies in Neotropical fish species. However, because atrazine and glyphosate are widespread contaminants of soil and water, their immune-stimulating effect could be harmful, in that fish living in herbicidecontaminated water might have increased concentrations of nonspecific antibodies that could mediate tissue injury.
\end{abstract}

Key words: Fish; Humoral response; Antibody production; Herbicides; Adjuvant

\section{Introduction}

Fish comprise one of the most diverse animal species and inhabit highly different environments in which a wide range of pathogens might be found. As such, fish responses and defense mechanisms to the challenge of microorganisms are also highly diverse. Hence, the ability of fish to cope with infecting pathogens relies on a delicate balance between the environment and the components of the innate and acquired immune systems.

In Teleostean fish, tissue macrophages are the main cells of the innate immune system and represent one of the first and most important barriers to bacterial colonization. Macrophages also provide important signaling to lymphocytes, which play a central role in acquired immunity (1), which is mediated in part by soluble tetrameric, IgM-like immunoglobulins. Other classes of immunoglobulin have also been detected in fish, but their roles in specific defense have not yet been clearly demonstrated (2). Because of their major role in protection, the ideal condition for immunoglobulin production has been investigated in several fish species and, in some instances, it has been shown to be affected by environmental and management practices or the presence of xenobiotics such as agrichemicals (3).

Water bodies and soil samples located in the vicinity of agricultural areas might be contaminated with several types of herbicides and pesticides at concentrations that can be harmful to a variety of non-target organisms including fish. Atrazine (6-chloro-N2-ethyl-N4isopropyl-1,3,5-triazine-2,4-diamine) and glyphosate ( $N$-phosphonomethyl glycine) are among the most widely used agrichemicals in soybean and corn fields, and their toxicity to silver catfish (Rhamdia quelen), an indigenous fish species endemic in South American rivers and lakes, has already been demonstrated. Exposure of silver catfish

Correspondence: L.C. Kreutz, Faculdade de Agronomia e Medicina Veterinária, Universidade de Passo Fundo, Campus I, $99052-100$ Passo Fundo, RS, Brasil. Fax: +55-54-3316-8163. E-mail: Ickreutz@upf.br 
to sublethal concentrations of herbicides alters hormonal profiles (4), causes oxidative stress (5), liver and kidney damage (6), and affects blood cells and innate immunological functions $(7,8)$. Current data indicate that these agrichemicals have the potential to alter silver catfish general metabolism and the ability of the innate immune system to protect against bacterial infections.

Immunoglobulin production in fish might be altered by environmental factors, and previous studies indicated a deleterious effect of selected agrichemicals on catfish defense mechanisms (7). Here, we aimed to investigate the kinetics of immunoglobulin secretion and whether different water temperatures, boosting vaccination, and the presence of atrazine and glyphosate-based herbicides would have any impact on the production of antibodies to Aeromonas hydrophila, a Gram-negative bacterium frequently isolated from fish presenting hemorrhagic and ulcerative syndromes. We found that the kinetics of immunoglobulin production was similar in fish kept at the two different water temperatures used in the experiment and that no recall response was obtained following booster vaccination. However, an intriguing finding was that both atrazine and glyphosate had a stimulating effect on immunoglobulin production, in that higher titers of specific antibodies were observed in the serum of vaccinated, agrichemical-exposed fish.

\section{Material and Methods}

The first experiment was designed to investigate the kinetics of antibody production and the effect of water temperature and booster immunization. During the acclimatization period of 7 days, and up to the end of the experiment, fingerlings $(32.2 \pm 6.7 \mathrm{~g} / 14.3 \pm 1.1 \mathrm{~cm})$ were kept in self-cleaning tanks containing 2000 liters of continuously running water at the indicated temperatures. One group of fingerlings $(n=70)$ was inoculated intraperitoneally with $0.1 \mathrm{~mL}$ inactivated $A$. hydrophila $\left(2 \times 10^{8} \mathrm{CFU} /\right.$ $\mathrm{mL}$ ) and placed in water at non-controlled, environmental temperature (Aeromonas-inoculated, $17.4 \pm 0.4^{\circ} \mathrm{C}$ ). A second group of fingerlings $(n=70)$ was inoculated with the same amount of antigen and placed in heated water (Aeromonas-inoculated, $21.3 \pm 0.3^{\circ} \mathrm{C}$ ). Saline-inoculated control fish were tagged and placed in water at environmental temperature $(n=18$; saline-inoculated, 17.4 $\left.\pm 0.4^{\circ} \mathrm{C}\right)$ or heated water $(n=17$; saline-inoculated, 21.3 $\pm 0.3^{\circ} \mathrm{C}$ ). At 21 days after primary immunization, 21 fingerlings from each Aeromonas-inoculated group were boosted with the same amount of bacteria and transferred to separate tanks with water at the respective temperatures.

Blood samples were collected from at least 7 fish of each group prior to inoculation on day 0 , and at 7-day intervals up to 35 days, when the experiment was finished. At each time, fish captured for blood sampling were removed from the experiment. Boosted fingerlings were also sampled at 7-day intervals (days 28 and 35).

The second experiment consisted of a static bioassay that aimed to investigate the effect of atrazine or glyphosate on the production of specific antibodies. Prior to immunization, fingerlings were acclimatized for 7 days in tanks containing chlorine-free, continuously aerated tap water $\left(22.1 \pm 0.7^{\circ} \mathrm{C}\right)$. During the entire experiment, fish density was kept lower than $1 \mathrm{~g}$ fish per liter of water. The concentration of atrazine and glyphosate added to the water was equivalent to $10 \%$ of the previously reported lethal concentration ( $\mathrm{LC}_{50-96 h}$ ) (8) for silver catfish (1.02 mg/L for atrazine and $0.730 \mathrm{mg} / \mathrm{L}$ for glyphosate).

After the acclimation period, 30 fingerlings were inoculated with sterile saline solution and placed in tanks containing atrazine (saline-inoculated atrazine, $n=15$ ) or glyphosate (saline-inoculated glyphosate, $n=15$ ) and evaluated as the saline-inoculated herbicide-exposed (S-HE) control group. The remaining fingerlings $(n=90)$ were inoculated intraperitoneally with $0.1 \mathrm{~mL}$ inactivated A. hydrophila $\left(2 \times 10^{8} \mathrm{CFU} / \mathrm{mL}\right)$ and distributed equally in nine tanks (10 fish/tank) as three treatments in triplicate: tanks without herbicides (Aeromonas-inoculated herbicidefree, $A h-\mathrm{HF})$, tanks containing atrazine (Aeromonasinoculated atrazine, Ah-Atr), or tanks with glyphosate (Aeromonas-inoculated glyphosate, Ah-Gly). All tanks were cleaned every 2 days by bottom suction, and the amount of water removed by cleaning (approximately 10\% of the volume) was replaced using water from tanks containing the same concentration of herbicides, or herbicide-free water. Water conditions in all tanks were monitored throughout the experiment and were maintained within normal parameters as reported previously (7).

After 21 days, all fish were captured for blood sampling. Culturing and inactivation of $A$. hydrophila, blood sampling, and the serum agglutination assay were performed as reported previously (7). Total serum protein and immunoglobulin concentrations were determined by standard methods as already published (9). The results obtained were analyzed by the Shapiro-Wilk test ( $P>0.05)$ using SPSS statistics version 19 (IBM Corp., USA) and were found to have a normal distribution. Differences among treatments were analyzed by two-way ANOVA followed by the Bonferroni multiple comparisons test, and plotted using the GraphPad Prism Statistics Software v. 5 (GraphPad Software, Inc., USA). P values of 0.05 or less were considered to be significant. Results are reported as means $\pm S E$.

The experiments were carried out according to the guidelines of Colégio Brasileiro de Experimentação Animal and were approved by the Ethics Committee for the Care and Use of Experimental Animals of Universidade de Passo Fundo, Brazil.

\section{Results and Discussion}

Here we provide the first report related to the kinetics 
of antibody production in silver catfish ( $R$. quelen) in response to inoculated antigen. Fish immunized with $A$. hydrophila bacterin had a sharp and significant $(P<0.05)$ increase of specific serum antibodies as soon as 7 days post-inoculation (Figure 1). Antibody titers continued to increase steadily for up to 35 days, when the experiment was concluded. Anti-aeromonid agglutinating antibodies in saline-inoculated fish remained at basal levels throughout the experiment (Figure 1) and were within the range reported in previous studies (7) of non-immunized fish.

The kinetics and timing of maximum antibody response to inoculated antigen is central to vaccine development and vaccination strategies. In general, fish antibody response to bacteria-derived antigens occurs within a few days and reaches maximum levels 4 to 5 weeks following priming, as reported here. A similar response has been observed in Indian major carp (Labeo rohita) and turbot (Scophthalmus maximus) inoculated with different combinations of adjuvants and bacterial antigens, including $A$. hydrophila $(10,11)$. Higher antibody titers, however, are usually obtained following inoculation with antigens emulsified in Freund's complete adjuvant,

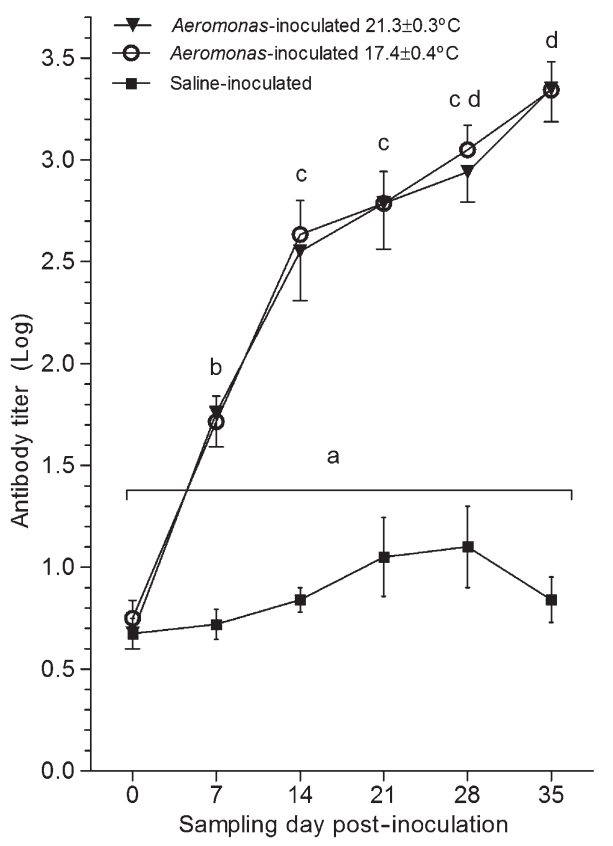

Figure 1. Kinetics of specific antibody production in silver catfish following intraperitoneal inoculation with inactivated Aeromonas hydrophila or sterile saline and kept at different water temperatures. Serum samples were collected prior to immunization (day 0 ) and at 7-day intervals. The results obtained from salineinoculated fish kept at different temperatures were similar and were combined in a single group. Data are reported as the logarithm ( \pm SE) of the last serum dilution that caused bacterium agglutination and were compared using two-way ANOVA and the Bonferroni post-test. Significant differences $(P<0.05)$ are indicated by different letters at each time point. indicating that antibody secretion depends partly on the nature of antigen and proper presentation to B lymphocytes. Fish immunized with T-cell-dependent antigens, such as some viral or parasite-derived proteins might have a lower and delayed humoral response (12).

Because antibody titers in fish are believed to be shortlived, there is major concern related to the requirements for antigen reinoculation. A recall response to vaccination might be demonstrated by rising antibody titers following reinoculation of antigens. Immunological memory has been demonstrated in rainbow trout (Oncorhynchus mykiss) inoculated with a T-cell-dependent antigen (12). Here, however, reinoculation of $A$. hydrophila at 21 days after priming had no effect on subsequent antibody titers at both temperatures tested (data not shown). Because at 21 days after priming, anti-aeromonid antibodies were already relatively high and steadily increasing, as shown in the kinetics curve (Figure 1), they could have inhibited further stimulation of memory $B$ lymphocytes. In addition, whole bacteria such as inactivated $A$. hydrophila, comprise mostly T-independent antigens, and, therefore, a booster inoculation might not be required to raise antibody levels. Further experiments, using non-related bacterial antigens free of endotoxins and different reinoculation schedules and adjuvant combinations, should provide more information that might improve our understanding on this subject.

Because antibody production might be influenced by several different factors, we investigated whether water temperature would impact the humoral response. As depicted in Figure 1, we were unable to find differences in anti-aeromonid antibody titers at any sampling time in immunized fish kept at different temperatures. Even though the difference of water temperature in the tanks $\left(17.4 \pm 0.4^{\circ}\right.$ vs $\left.21.3 \pm 0.3^{\circ} \mathrm{C}\right)$ was relatively small $\left( \pm 4^{\circ} \mathrm{C}\right)$, it represented realistic temperature variations found during the end of fall, throughout winter, and in early spring. Indeed, seasonal differences in water temperature at a local hydroelectric plant (latitude $28^{\circ} 15^{\prime} \mathrm{S}$; longitude $52^{\circ} 24^{\prime} \mathrm{W}, 687 \mathrm{~m}$ above sea level) ranged from $26.2^{\circ}$ to $28.9^{\circ} \mathrm{C}$ in summer, $24.2^{\circ}$ to $26.2^{\circ} \mathrm{C}$ in fall, $16.5^{\circ}$ to $17.7^{\circ} \mathrm{C}$ in winter, and $22.6^{\circ}$ to $25.1^{\circ} \mathrm{C}$ in spring (13). The effect of water temperature on immune response is central to vaccine development. In general, lower water temperatures reduce antibody production in most fish species studied. In non-vaccinated Nile tilapia (Oreochromis niloticus) kept at $28^{\circ} \mathrm{C}$ for 2 weeks, the immunoglobulin levels were higher than in fish kept at $23^{\circ} \mathrm{C}(14)$. In the channel catfish (Ictalurus punctatus) no antibodies to Ichthyophthirius multifilis could be detected in immunized fish kept for 21 days at $15^{\circ} \mathrm{C}$ or at temperatures cycling from $15^{\circ}$ to $25^{\circ} \mathrm{C}$ (15). However, at higher temperatures $\left(25^{\circ}\right.$ and $\left.30^{\circ} \mathrm{C}\right)$ a robust and protective immune response was observed. In Japanese flounder (Paralichthys olivaceus) intraperitoneally vaccinated with inactivated virus, maximum immunoglobulin production was found in fish 
kept at $21^{\circ} \mathrm{C}$; lower $\left(9^{\circ}\right.$ to $\left.15^{\circ} \mathrm{C}\right)$ or higher temperatures $\left(26^{\circ} \mathrm{C}\right)$ had a deleterious effect on the production of circulating immunoglobulin (16). In fact, water temperature below $15^{\circ} \mathrm{C}$ decreases immunoglobulin production in several other fish species such as sea bass (Dicentrarchus labrax), Atlantic halibut (Hippoglossus hippoglossus), summer flounder (Paralichthys dentatus), Japanese flounder, Nile tilapia and carp (Cyprinus carpio) (17) when compared with higher temperatures $\left(18^{\circ}\right.$ to $23^{\circ} \mathrm{C}$ ). It should be noted, however, that, for fish species adapted to colder temperatures, increasing the temperature does not improve the acquired immune response. Thus, current data indicate that immunoglobulin production is indeed affected by water temperature but that each fish species has a temperature range at which the acquired immune response might be optimal. The silver catfish is perfectly adapted to seasonal temperature variation but is more active in the warmer months of the year. Thus, we cannot rule out the possibility that, at higher temperatures, differences in antibody production might be detected in immunized fish. However, the temperatures used in our experiments were within the range found throughout the year. In addition, we used bacterin antigens that per se are excellent particulate antigens in fish and might not require boosting immunization to maintain high levels of serum antibodies. Hence, the effect of temperature on the kinetics of immunoglobulin production should be further investigated using purified soluble antigens, adjuvant combinations, and fish kept at a wider range of temperatures, such as those found during late summer. However, regardless of season and water temperature, fish should always be immunized prior to any possible encounter with a pathogenic microorganism, which is usually dictated by husbandry management at each farm.

In previous research, we demonstrated that the presence of glyphosate and atrazine reduced fish survival after challenging with $A$. hydrophila, and had a deleterious effect on innate immune functions $(7,8)$. Here, we wanted to know whether antibody production would be affected under similar experimental conditions. Unexpectedly, fish inoculated with $A$. hydrophila and exposed to atrazine (Ah-Atr) or glyphosate ( $A h$-Gly) had significantly $(P<0.05)$ higher antibody responses compared to inoculated but non-exposed fish ( $A h$-HF; Figure 2). Although total serum proteins were similar among all groups (Figure 3), immunoglobulin concentrations were significantly higher $(\mathrm{P}<0.05)$ in the Ah-Atr and Ah-Gly groups.

The intriguing effect of atrazine and glyphosate on acquired humoral immune responses is in sharp contrast with the deleterious effect they have on the innate immune system $(7,8)$. An insight into the mechanisms underlying the immune stimulating effect of herbicides was recently reported in Nile tilapia (O. niloticus). Following inoculation with $A$. hydrophila, Nile tilapia

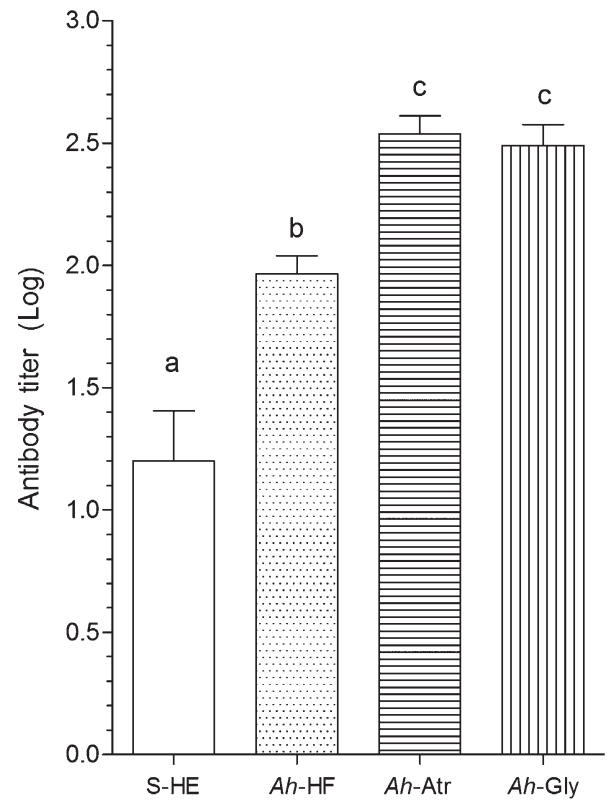

Figure 2. Exposure to atrazine or glyphosate increases the production of antibodies in silver catfish. Fingerlings were inoculated with inactivated Aeromonas hydrophila and kept on herbicide-free water $(A h-\mathrm{HF})$, exposed to atrazine or glyphosate (Ah-Atr and $A h$-Gly, respectively) or inoculated with saline and exposed to herbicides (S-HE). Data from the S-HE represents all data from saline-inoculated fish exposed to either atrazine or glyphosate. Data are reported as means \pm SE. The results are shown as the logarithm of the last serum dilution that caused bacterium agglutination. One-way ANOVA and the Bonferroni post-test were used to compare the data and significant differences $(P<0.05)$ are indicated by different letters.

exposed to endosulfan had higher anti-aeromonid antibody titers than the non-exposed inoculated group (18). In addition, the endosulfan-exposed group had higher levels of interleukin-2 (IL-2)-like factor that could have stimulated lymphocytes in a nonspecific manner and contributed to the increased immunoglobulin production. In fact, IL-2 might be important for immunoglobulin production in fish, in that Nile tilapia and rainbow trout challenged with $A$. hydrophila had increased levels of IL-2 compared to non-challenged groups. The effects of atrazine and glyphosate on immune cells and cytokine expression have not been widely investigated. However, in a mammalian model, atrazine-exposed BALB/c mice had higher levels of IgM-secreting cells in the spleen and increased cytotoxic lymphocyte function and proliferative response of splenocytes after in vivo stimulation (19), indicating a potential for nonspecific immune stimulation. Increased levels of IL-1 $\beta$ and IL-1 receptor mRNA, mainly in spleen and head kidney, were detected in common carp exposed to atrazine (20). Thus, because IL-1 $\beta$ is a cytokine with pleiotropic effects and central to early stimulation of the immune response, exposure of fish 


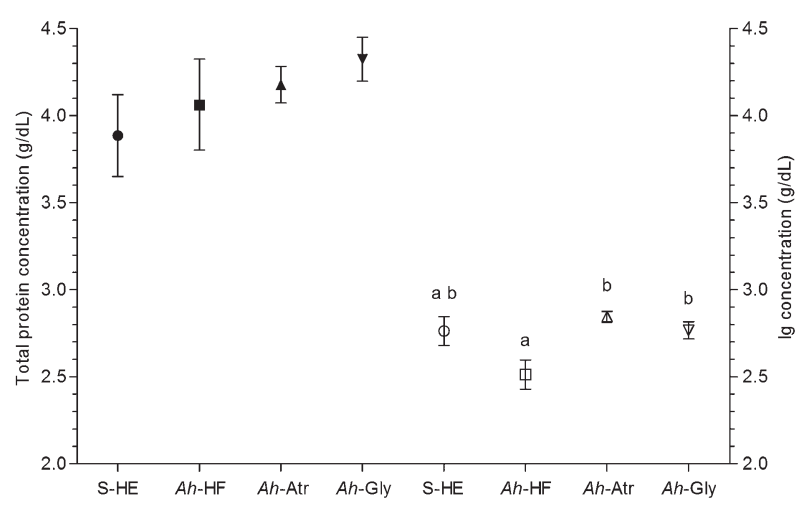

Figure 3. Total serum proteins (closed symbols) and immunoglobulins (open symbols) from silver catfish fingerlings (for details, see Figure 2). Data are reported as means $\pm S E$. Oneway ANOVA and the Bonferroni post-test were used to compare the data and significant differences $(P<0.05)$ are indicated by different letters.

to atrazine could induce a nonspecific stimulation of lymphocytes and contribute to an increase of antibody titers. In fact, we noticed that serum agglutination activity against $A$. hydrophila was relatively higher in salineinoculated herbicide-exposed fish (S-HE; Figure 2) compared to saline-inoculated fish in experiment 1 (Figure 1) and similar to that found in previous experiments (8). Nonspecific antibodies that could have been induced in the presence of the agrichemical per se, as previously discussed, might account for this agglutination activity. Consistent with this, S-HE fish had higher immunoglobulin concentrations than Ah-HF fish (Figure 3). Because total serum proteins in S-HE fish were similar to those in the other groups, the possibility that atrazine or glyphosate induced a general increase in protein synthesis might be ruled out.

Therefore, even though the stimulatory effect of atrazine and glyphosate should be of concern because their presence in the water might lead to continuous

\section{References}

1. Aoki T, Takano T, Santos MD, Kondo H. Molecular innate immunity in teleost fish? Review and future perspectives. Fish Glob Welf Environ 2008; 263-276. http://www.terrapub. co.jp/onlineproceedings/fs/wfc2008/pdf/wfcbk_263.pdf. Accessed June 19, 2013.

2. Fillatreau S, Six A, Magadan S, Castro R, Sunyer JO, Boudinot $P$. The astonishing diversity of Ig classes and $B$ cell repertoires in teleost fish. Front Immunol 2013; 4: 28, doi: 10.3389/fimmu.2013.00028.

3. Bowden TJ. Modulation of the immune system of fish by their environment. Fish Shellfish Immunol 2008; 25: 373-3 83, doi: 10.1016/j.fsi.2008.03.017.

4. Cericato L, Neto JG, Kreutz LC, Quevedo RM, da Rosa JG, Koakoski G, et al. Responsiveness of the interrenal tissue of Jundia (Rhamdia quelen) to an in vivo ACTH test following production of pro-inflammatory cytokines, the molecular mechanism behind this stimulation might be of general interest to immunologists. Indeed, the concept that even toxic substances at low doses might have beneficial effects on exposed individuals is becoming widely recognized. Nonetheless, it should be kept in mind that nonspecific stimulation of lymphocytes and the generation of nonspecific antibodies might cause cell damage, mainly in the spleen and head kidney, and trigger or lead to autoimmune diseases.

In summary, our results demonstrate that silver catfish inoculated with $A$. hydrophila bacterin produce a quick and robust humoral response that is not affected by small differences in water temperature or recall vaccination at 21 days after priming. An understanding of the requirements for optimal antibody secretion is central to the development of effective vaccines and vaccination strategies in Neotropical fish species such as catfish. However, the most intriguing finding was that the presence of atrazine or glyphosate in the water increased the production of antibodies to $A$. hydrophila in vaccinated fish, extending our previous observation that atrazine or glyphosate-exposed silver catfish have higher serum immunoglobulins compared with fish kept in herbicide-free water. The effect of agrichemicals on the expression of cytokines and immune-related genes should be a subject of further investigation aiming to better understand the effects of agrichemicals on the fish immune system.

\section{Acknowledgments}

Research supported by CNPq (\#473195/2010-0). T.R. Pavan is a Master Student with a CAPES fellowship (\#2013/1236). A.G. Alves was supported by a Probic/ FAPERGS fellowship (\#11/0461-6). L.J.G. Barcellos was the recipient of a CNPq research fellowship (\#302073/ 2011-6)

acute exposure to sublethal concentrations of agrichemicals Comp Biochem Physiol C Toxicol Pharmacol 2009; 149: 36 3-367, doi: 10.1016/j.cbpc.2008.09.002.

5. Ferreira D, da Motta AC, Kreutz LC, Toni C, Loro VL, Barcellos LJ. Assessment of oxidative stress in Rhamdia quelen exposed to agrichemicals. Chemosphere 2010; 79: 914-921, doi: 10.1016/j.chemosphere.2010.03.024.

6. Mela M, Guiloski IC, Doria HB, Randi MA, de Oliveira Ribeiro CA, Pereira L, et al. Effects of the herbicide atrazine in neotropical catfish (Rhamdia quelen). Ecotoxicol Environ Saf 2013; 93: 13-21, doi: 10.1016/j.ecoenv.2013.03.026.

7. Kreutz LC, Gil Barcellos LJ, de Faria V, de Oliveira Silva T, Anziliero D, Davi dos Santos E., et al. Altered hematological and immunological parameters in silver catfish (Rhamdia quelen) following short term exposure to sublethal concen- 
tration of glyphosate. Fish Shellfish Immunol 2011; 30: 5157, doi: 10.1016/j.fsi.2010.09.012.

8. Kreutz LC, Barcellos LJ, Marteninghe A, Dos Santos ED, Zanatta R. Exposure to sublethal concentration of glyphosate or atrazine-based herbicides alters the phagocytic function and increases the susceptibility of silver catfish fingerlings (Rhamdia quelen) to Aeromonas hydrophila challenge. Fish Shellfish Immunol 2010; 29: 694-697, doi: 10.1016/ j.fsi.2010.06.003.

9. Siwicki AK, Anderson DP, Rumsey GL. Dietary intake of immunostimulants by rainbow trout affects non-specific immunity and protection against furunculosis. Vet Immunol Immunopathol 1994; 41: 125-139, doi: 10.1016/0165-2427 (94)90062-0.

10. Swain P, Behura A, Dash S, Nayak SK. Serum antibody response of Indian major carp, Labeo rohita to three species of pathogenic bacteria; Aeromonas hydrophila, Edwardsiella tarda and Pseudomonas fluorescens. Vet Immunol Immunopathol 2007; 117: 137-141, doi: 10.1016/j.vetimm. 2007.02.010.

11. Zheng Z, Yingeng W, Qingyin W, Nannan D, Meijie L, Jiangbo $Q$, et al. Study on the immune enhancement of different immunoadjuvants used in the pentavalent vaccine for turbots. Fish Shellfish Immunol 2012; 32: 391-395, doi: 10.1016/j.fsi.2011.11.014.

12. Arkoosh MR, Kaattari SL. Development of immunological memory in rainbow trout (Oncorhynchus mykiss). I. An immunochemical and cellular analysis of the B cell response. Dev Comp Immunol 1991; 15: 279-293, doi: 10.1016/0145-305X(91)90021-P.

13. Hahn L, Camara LF da. Qualidade da água do reservatório da usina hidrelétrica de Passo Fundo, RS. Tractebel EnergiaSuez 2003; 3: 3. http://www.tractebelenergia.com.br/wps/ wcm/connect/5dfad7eb-fbcf-4f45-a209-2f317da8927b/ 8.pdf?MOD = AJPERES\&CACHEID = 5dfad7eb-fbcf-4f45-a2 09-2f317da8927b. pdf. Accessed August 3, 2013.

14. Dominguez M, Takemura A, Tsuchiya M, Nakamura $S$. Impact of different environmental factors on the circulating immunoglobulin levels in the Nile tilapia, Oreochromis niloticus. Aquaculture 2014; 241: 491-500, doi: 10.1016/ j.aquaculture.2004.06.027.

15. Martins $\mathrm{ML}, \mathrm{Xu} \mathrm{DH}$, Shoemaker CA, Klesius $\mathrm{PH}$. Temperature effects on immune response and hematological parameters of channel catfish Ictalurus punctatus vaccinated with live theronts of Ichthyophthirius multifiliis. Fish Shellfish Immunol 2011; 31: 774-780, doi: 10.1016/ j.fsi.2011.07.015.

16. Xu G, Sheng X, Xing J, Zhan W. Effect of temperature on immune response of Japanese flounder (Paralichthys olivaceus) to inactivated lymphocystis disease virus (LCDV). Fish Shellfish Immunol 2011; 30: 525-531, doi: 10.1016/j.fsi.2010.11.026.

17. Bowden TJ, Thompson KD, Morgan AL, Gratacap RM, Nikoskelainen S. Seasonal variation and the immune response: a fish perspective. Fish Shellfish Immunol 2007; 22: 695-706, doi: 10.1016/j.fsi.2006.08.016.

18. Tellez-Banuelos MC, Santerre A, Casas-Solis J, Zaitseva G. Endosulfan increases seric interleukin-2 like (IL-2L) factor and immunoglobulin M (IgM) of Nile tilapia (Oreochromis niloticus) challenged with Aeromona hydrophila. Fish Shellfish Immunol 2010; 28: 401-405, doi: 10.1016/j.fsi.2009.11.017.

19. Rowe AM, Brundage KM, Schafer R, Barnett JB. Immunomodulatory effects of maternal atrazine exposure on male Balb/c mice. Toxicol Appl Pharmacol 2006; 214: 69-77, doi: 10.1016/j.taap.2005.12.006.

20. Wang $X$, Xing $H$, Li X, Xu S, Wang X. Effects of atrazine and chlorpyrifos on the mRNA levels of IL-1 and IFN-gamma2b in immune organs of common carp. Fish Shellfish Immunol 2011; 31: 126-133, doi: 10.1016/j.fsi.2011.04.015. 